\title{
ACABAR COM A META DE SUPERÁVIT É IRRESPONSABILIDADE FISCAL
}

Coluna publicada em 18.11.2014: <http://www.conjur.com.br/2014-nov-18/ contas-vista-acabar-meta-superavit-irresponsabilidade-fiscal $>$

Já destaquei neste espaço a importância da Lei de Diretrizes Orçamentárias (LDO) como instrumento de planejamento e gestão fiscal. ${ }^{1}$ Mas foi necessário um ato de falta de planejamento e irresponsabilidade na gestão fiscal para trazer o assunto à mídia, chamando a atenção de todos para essa lei tão relevante que poucos conhecem.

Menos mal. Pelo menos, está tendo sua importância reconhecida.

$\mathrm{Na}$ semana passada a mídia foi tomada pelas notícias e debates sobre o projeto de alteração da Lei de Diretrizes Orçamentárias para $2014^{2}$ enviado pela Presidente da República ao Congresso Nacional, com a finalidade de permitir a redução da meta de superávit.

A LDO, instrumento jurídico próprio da legislação brasileira, cuja finalidade precípua é estabelecer os parâmetros para a lei orçamentária a ser aprovada no final de cada exercício financeiro, tem cumprido atualmente várias funçōes importantes para o planejamento e gestão do setor público. Já me referi a elas na coluna citada e, entre todas, destaco aquelas que lhe foram atribuídas pela Lei de Responsabilidade Fiscal $(\mathrm{LRF})^{3}$ e são relevantes para compreender o que se discute. Cabe à LDO dispor sobre o equilíbrio de receitas e despesas (LRF, artigo $4^{\circ}, \mathrm{I}, a$ ) e vir acompanhada do Anexo de Metas Fiscais, "em que serão estabelecidas metas

1 Coluna LDO é instrumento eficiente para a administração pública, publicada em 9 de abril de 2013.

2 Lei 12.919, de 24 de dezembro de 2013.

3 Lei Complementar 101, de 4 de maio de 2000. 
anuais, em valores correntes e constantes, relativas a receitas, despesas, resultados nominal e primário e montante da divida pública, para o exercício a que se referirem e para os dois seguintes" (LRF, artigo $4^{\circ}, \$ 1^{\circ}$ ).

Trata-se de uma regra de grande relevância para o planejamento do setor público, por indicar e estabelecer metas que vão balizar o comportamento da administração pública nos exercícios financeiros que se seguem, que servirá para orientar não só a administração pública federal, mas também fornecer parâmetros aos demais entes da federação e o próprio setor privado, além de todos os atores com os quais o país se relaciona, internamente e também do exterior.

Cumpre destacar que as metas fiscais são importantes, na medida em que o descumprimento delas permite verificar, ainda que de forma indireta, a desobediência a uma série de outros deveres de equilíbrio fiscal previstos na LRF, não se restringindo ao desrespeito ao dever de cumprir as metas previstas no artigo $4^{\circ}, \$ 1^{\mathrm{o}}$. Nessa conduta estão pressupostas lesões a vários de seus comandos. É o caso, por exemplo, das renúncias de receitas, cuja concessão tem como condição de validade para sua instituição a comprovação de não afetação das metas fiscais, o que, se ocorrer, deve ser compensado mediante a instituição de novo tributo ou majoração de alíquota ou base de cálculo de tributo já existente (LRF, artigo 14). Lembre-se ainda que a criação, expansão ou aprimoramento de qualquer ação governamental que implique aumento de despesa está vinculada à compatibilidade com as metas fiscais, as quais - se forem afetadas por mais de dois exercícios por meio da geração de despesa definida em ato normativo - devem ser compensadas proporcionalmente por meio da redução permanente de despesa ou majoração permanente de receita (LRF, artigo $17, \$ 2^{\circ}$ ).

Tudo isso demonstra o caráter estruturante das metas fiscais para o equilíbrio das contas públicas. Se elas não são cumpridas, todas as demais áreas de gestão de receita e de despesa são presumidamente irregulares, lesivas ao erário e não autorizadas, na forma do artigo 15 da própria LRF.

A LDO para 2014, publicada (com grande atraso) no final de 2013, em seu artigo $2^{\circ}$, estabeleceu que o orçamento a ser aprovado para o exercício de 2014 (atualmente no final de sua vigência), deveria ser compatível com a obtenção da meta de superávit primário de $\mathrm{R} \$ 116$ bilhōes, fazendo constar, em seu artigo $3^{\circ}$, a possibilidade de reduzir esse montante em até $\mathrm{R} \$ 67$ bilhôes em função de despesas do Programa de Aceleração do Crescimento (PAC) e desonerações de tributos.

É fato que as leis de natureza orçamentária, por compreenderem previsões de receitas e despesas futuras, ficam sujeitas a uma série de fatores nem sempre controláveis e previsíveis, sendo leis cujo cumprimento não é possível exigir com o ri- 
gor que se espera das demais normas que compõem o ordenamento jurídico. Isso, no entanto, não lhes tira o caráter impositivo, a ponto de transformá-las em leis de natureza meramente autorizativa, sem qualquer caráter mandatório. ${ }^{4}$ Há que se reconhecer nelas, tão somente, a necessidade de serem dotadas de mecanismos de flexibilidade, cuja finalidade é apenas permitir sua adaptação às circunstâncias que levam à necessidade de ajustes, mas sem descaraterizá-las, mantendo hígidos seus dispositivos, sob pena de torná-las peças de ficção e instrumentos inúteis para o planejamento, gestão e controle da atividade financeira da administração pública, funções que a Constituição lhes atribuiu.

Pois o projeto de lei ora apresentado 5 está na contramão de tudo o que estabelecem a Constituição e os princípios de planejamento, gestão e controle da administração pública, promovendo inaceitável insegurança jurídica e minando a credibilidade do governo perante todos.

Propõe a alteração do artigo $3^{\circ}$ da LDO de 2014, anteriormente citado, retirando os valores das metas, passando a estabelecer que a "meta de superávit poderá ser reduzida no montante das desonerações de tributos e dos gastos relativos ao PAC”. Ou seja: acabando com as metas. Onde havia metas, agora não há mais nada.

É razoável admitir que as leis orçamentárias, entre as quais a LDO, sejam dotadas de alguma flexibilidade, dada as necessárias adaptações, como já dito, desde que não comprometam o conteúdo dos dispositivos legais. No caso, o dispositivo legal, mais do que comprometido, foi inutilizado, pois o que se pretende é extinguir as metas nele previstas - que, ressalte-se, já continham no seu bojo uma grande possibilidade de flexibilidade, facultando-se significativa redução do valor das metas.

Justificativa? Diz a mensagem encaminhadora do projeto que, ao longo de 2014, foi reduzido o ritmo de crescimento da economia, tornando necessário aumentar os incentivos fiscais e manter investimentos para permitir a retomada do crescimento.

Difícil acreditar que os equívocos na previsão sobre a atividade financeira da administração pública federal tenham sido tão significativos e imprevisíveis, tornando inviável cumprir a meta de superávit anteriormente fixada, ainda que diminuída ao máximo pela redução nela mesma prevista. E, para serem reais esses fatos, em muito ficaria comprometida a capacidade dos órgãos governamentais

4 Como já escrevi anteriormente na coluna Orçamento impositivo é avanço para a administração, publicada em 7 de maio de 2013.

5 Projeto de Lei 36, de 2014 - CN, mensagem 365, de 104 - na origem. 
encarregados de analisar os cenários da economia e fazer as previsóes. Some-se a isso a sabida tendência de aumentar gastos em ano eleitoral, associada ao encaminhamento dessa proposta de alteração da lei logo após as eleições, para compor um quadro que não permite crer serem esses os verdadeiros motivos que ensejam a tentativa de modificar a LDO.

Tudo indica que, neste ano eleitoral, houve exagero nos gastos, comprometendo o cumprimento das metas e, agora, constatada a inviabilidade de serem atingidas, o que se pretende é extingui-las, evitando a violação clara e inequívoca do texto da lei, para tentar escapar das possíveis sanções daí decorrentes.

$\mathrm{O}$ ordenamento jurídico está sendo posto à prova. Leis existem para serem cumpridas. A eficiência da administração pública depende de um planejamento dotado de segurança jurídica, bem elaborado e dotado de credibilidade, sem o que a gestão e o controle ficam seriamente comprometidos. A LDO tem se mostrado um instrumento relevante nesse processo. As metas previstas na LDO para 2014 deveriam ser cumpridas até o final deste exercício financeiro de 2014, que está a poucas semanas do fim. Acabar com elas é fazer dessa função da LDO, cuja importância é crescente, verdadeira letra morta.

Mas não é só, infelizmente.

Ao modificar critérios para o cálculo das metas de superávit primário, com a inclusão de itens como desonerações de tributos, cujos cálculos são pouco precisos e complexos, despesas do PAC, também sujeitas a elevado grau de discricionariedade, o governo compromete a seriedade desses valores, abrindo margem à "contabilidade criativa”, que parece estar se tornado uma praxe nos últimos anos, à qual já me referi por mais de uma vez em colunas anteriores, ${ }^{6}$ causando prejuízos irremediáveis à segurança jurídica e à credibilidade do país nos cenários interno e externo, o que só torna a situação ainda mais grave.

É fato que o Congresso Nacional tem sido leniente com suas responsabilidades em matéria orçamentária. $\mathrm{Na}$ aprovação da lei orçamentária, pouco interfere no projeto apresentado pelo Poder Executivo, contentando-se com uma pequena cota que lhe é concedida para as emendas parlamentares, utilizadas para destinar recursos a uma ou outra dotação que possa interessar a seus eleitores, deixando de apreciar as despesas de grande monta das principais políticas públicas.

6 Reporto-me especialmente às colunas Carnaval financeiro: contas "maquiadas" não vão deixar nosso país mais bonito, publicada em 12 de fevereiro de 2013, e Atenção caro leitor, pedalar faz mal à saúde!, publicada em 23 de setembro de 2014.

7 Sobre o assunto, falei na coluna Emendas ao orçamento e o desequilibrio de poderes, publicada em 3 de julho de 2012. 
Não tem apreciado e aprovado a tempo as propostas de leis de diretrizes orçamentárias, que são encaminhadas, na esfera federal, no dia 15 de abril, e deveriam ser aprovadas até o final da primeira sessão legislativa, em junho. Só para que se tenha uma ideia, nos últimos dez anos, apenas para mencionar os casos mais graves, a LDO para 2007 foi aprovada em 29 de dezembro e a LDO para 2014, atualmente vigente, em 24 de dezembro. Já estamos em meados de novembro, e a LDO para 2015 ainda não foi aprovada.

Precisa agir com mais rigor em sua função como responsável pelo controle externo (CF, art. 71), rejeitando, se o caso, as contas anuais do Presidente da República, quando não observadas as disposições legais - o que pode ocorrer pelo descumprimento injustificado dos comandos da LDO.

O fato é que o Congresso Nacional tem neste momento uma grande responsabilidade. Rejeitar esse projeto de lei é medida que se impõe para dar credibilidade e segurança ao ordenamento jurídico. Cabe-lhe agir com altivez para aplicar as sanções que lhe competem quando descumpridas as leis, mostrando que elas existem para serem respeitadas, especial e principalmente pelo Poder Executivo, ao qual não pode ser subserviente. 
